\title{
Mergers with Structural Remedies in a Cournot Oligopoly
}

\author{
Dongyu Guo \\ Graduate School of Management, NUCB Business School, Nagoya, Japan \\ Email: dongyu_guo@nucba.ac.jp
}

How to cite this paper: Guo, D. (2020). Mergers with Structural Remedies in a Cournot Oligopoly. Theoretical Economics Letters, 10, 366-383.

https://doi.org/10.4236/tel.2020.102025

Received: March 10, 2020

Accepted: April 23, 2020

Published: April 26, 2020

Copyright $\odot 2020$ by author(s) and Scientific Research Publishing Inc. This work is licensed under the Creative Commons Attribution International License (CC BY 4.0).

http://creativecommons.org/licenses/by/4.0/

\begin{abstract}
In a Cournot oligopolistic market, we investigate the social welfare effects of a one-shot bilateral merger with efficiency gains and structural remedies. The optimal merger policy trades off efficiency gains against market power. We show that a special case of structural remedies, namely, the divestiture of differentiated brands to an existing competitor, can be a powerful tool to lessen the merged entity's market power. As a consequence of the aforementioned trade-off, mergers with remedies can increase the scope for privately and socially desirable mergers, and lower efficiency gains from the merger require more divestitures to the competitor.
\end{abstract}

\section{Keywords}

Merger Policy, Structural Remedies, Divestiture

\section{Introduction}

Since the 1990s, when firms intend to merge, in addition to the "traditional" option to provide a merger proposal that the antitrust authority can either approve or block, the firms can also provide a merger proposal with remedies (or "commitments"), so that the antitrust authority can approve it in line with remedies. In the European Union, after the European Commission's (2001) "Notice on remedies", and in the US, after the Federal Trade Commission's (1999) "A Study of the Commission's Divestiture Process”, a considerable proportion of mergers are approved with remedies. For example, the European Commission (2014) states that "commitments are crucial instruments of merger control, since the large majority of cases that raise competition concerns are cleared with commitments rather than prohibited". There are similar trends in merger cases outside the European Union and the US. 
The purpose of remedies is that if the antitrust authority has concerns that a full merger may significantly affect competition in the common market (or a substantial part of it), certain modifications via remedies can guarantee continued competition. If the merger is approved, it may impede competition, but if it is blocked, society cannot enjoy efficiency gains from the merger. Hence, a merger with remedies can be a golden mean between a full merger and no merger.

There are two types of remedies: structural remedies and behavioral remedies. There is no generally accepted definition of structural and behavioral remedies in the literature. In this paper, we use the definitions formulated by Motta et al. (2003). Structural remedies modify the allocation of property rights and create new firms or enhance one or more existing firms. They include the divestiture of an entire on-going business or partial divestiture. Behavioral remedies entail the limitation of the merged entity's conduct.

Although both types of remedies have their pros and cons, there is a consensus that competitive concerns in horizontal mergers can be solved better by a structural remedy (OECD, 2011). The EU Remedy Notice (European Commission, 2008) states that "the most effective way to restore effective competition, apart from prohibition, is to create the conditions for the emergence of a new competitive entity or for the strengthening of existing competitors via divestiture". On the other hand, behavioral remedies would absorb the scarce resources of the antitrust authority because they require intensive monitoring. The remedial action chosen by the Federal Trade Commission in the US follows a relatively similar pattern. The empirical literature, as summarized in Table 1 by Bougette and Turolla (2008), has also shown that structural remedies constitute the most frequent type of remedies.

Table 1. Types of remedies in the European merger cases (1990-2005).

\begin{tabular}{ccccc}
\hline & Structural & Behavioral & Mixed & Total \\
\hline Phase I (in percentage of Phase I) & $62(54)$ & $36(31)$ & $17(15)$ & 115 \\
Phase II (in percentage of Phase II) & $26(36)$ & $18(25)$ & $28(39)$ & 72 \\
Total & 88 & 54 & 45 & 187 \\
\hline
\end{tabular}

This paper investigates structural remedies, with a focus on divestitures of one special form of assets: the divestiture of differentiated brands to an existing competitor. According to the merger guidelines issued by the UK Competition Commission (2008), "remedies that provide access to intellectual property (IP) by licensing or assignment of patents, brands or other IP rights may be viewed in general as a specialized form of asset divestiture"1. Mergers with brand divestitures are quite common nowadays, especially in large mergers. A prominent example is the acquisition of EMI Music by Universal Music Group, two of the four global major record companies with a value of $\$ 1.9$ billion in 2012. In compliance with the conditions of the European Commission, Universal Music ${ }^{1}$ Emphasis added. 
Group sold Mute catalogue to BMG, which constitutes the first completed divestiture from EMI Music buyout. Moreover, the merged entity sold Parlophone Music Group (minus the Beatles) to Warner Music Group and numerous other music brands to other existing competitors or new firms.

Williamson (1968) investigates the welfare trade-off between market power and efficiency gains generated by a merger. We prove that, in line with merger cases in the recent 20 years, remedies in merger policy are powerful tools to lessen the merged entity's market power. We investigate the important role of remedies in merger policy which can increase the scope for privately and socially desirable mergers. In particular, we show that when goods are closer to perfect substitutability, then the merging firms are more inclined to give some brands to competitor(s), because the markup on each brand is lower. Therefore the range of the efficiency gains which allows the merger with remedies to be approved is larger.

Despite of the practical evidence and the empirical case studies about the impact of remedies (e.g., Duso et al., 2011, 2013), still not enough attention has been devoted to the theoretical analysis of structural remedies.

Medvedev (2007) shows that if there are three firms in a homogeneous good market, the remedies with efficiency gains could extend the scope for merger acceptance. We extend this result to a differentiated good market and discuss a case of four firms. Vasconcelos (2010) analyzes remedies for four firms with efficiency gains. He finds that remedies may not serve consumer surplus as the antitrust authority is overshooting in terms of consumer protection, and an "over-fixing problem" can be caused by the antitrust authority. This phenomenon emerges when the antitrust authority over-fixes the anticompetitive effects of a merger and requires remedies even if the original merger (if unconditionally approved) would be consumer surplus improving. In our paper, we abstract from this "over-fixing problem", because, in line with the antitrust practices in most industrialized countries, we focus on the merger process instead of antitrust process, which implies that remedies are endogenously provided by merging firms.

Cabral (2003) analyzes mergers in a differentiated industry with free entry. If assets are sold to an entrant firm as a remedy, then a "buy them off" effect follows, which means an entrant firm is dissuaded from opening a new store (or introducing a new product variant). That effect may reduce the welfare of consumers, who are better off when more variants are offered. On the contrary, Dertwinkel-Kalt and Wey (2012) analyze the effects of structural remedies on merger activity in a Cournot oligopoly with a homogeneous good and find that the divestiture to an entrant firm is most effective in terms of consumer surplus. Our model focuses on the divestiture to the existing competitor(s) and excludes the entrant firm(s), so we can avoid this "buy them off" effect. This assumption is also in line with the empirical literatures (e.g., Papandropoulos and Tajana, 2006) that most of new entrants cannot survive in the market for long time even 
when they are given the divestitures by the merged entities.

The rest of the paper proceeds as follows. Section 2 sets out the basic model. Section 3 provides no merger case as a benchmark. Section 4 analyzes the conditions for approving a merger when there are three pre-merger firms and divestiture is given. Section 5 derives the optimal divestiture which is endogenously proposed by merging firms. Section 6 discusses a more general setting, where there are four pre-merger firms. Section 7 concludes and provides some future research directions.

\section{The Model}

Setting There are three symmetric Cournot oligopolists indexed by $j \in\{1,2,3\}$ in a market. Each firm produces $n \geq 2$ brands of substitute goods. To simplify the notation, firm $j$ produces the $j$-th. $n$ brands, so in total there are $3 n$ brands in the market ${ }^{2}$. Consider a one-shot bilateral merger with firm 1 as an acquirer and firm 2 as a target firm. We model the efficiency gains in a reduced form, as the merged entity enjoys the efficiency gains $X>0$ from the merger. For example, $X$ can be treated as efficiency gains based on the saving of fixed cost. Assume that the brands of the target firm may be given to the competitor, firm $3^{3}$. The number of brands that the merged entity keeps is $k$, where $k \in(n, 2 n]$.

Following Shubik and Levitan (1980), the gross consumer surplus is specified as

$$
U\left(q_{1}, \cdots, q_{3 n}\right)=\sum_{i=1}^{3 n} q_{i}-\frac{3 n}{2(1+\mu)}\left[\sum_{i=1}^{3 n} q_{i}^{2}+\frac{\mu}{3 n}\left(\sum_{i=1}^{3 n} q_{i}\right)^{2}\right],
$$

where $q_{i}$ is the quantity of the $i$-th. brand, and $\mu>0$ represents the degree of substitutability within the $3 n$ brands $s^{4}$.

Maximizing the utility function (1) subject to the income constraint yields the inverse demand function

$$
p_{i}\left(q_{1}, \cdots, q_{3 n}\right)=1-\frac{1}{1+\mu}\left(3 n q_{i}+\mu \sum_{l=1}^{3 n} q_{l}\right) .
$$

Firm $j$ s profit is

$$
\Pi_{j}=\sum_{i=1}^{B}\left[p_{i}\left(q_{1}, \cdots, q_{3 n}\right) q_{i}\right],
$$

where $B$ is the number of brands that firm $j$ has ${ }^{5}$.

Timing and equilibrium concept The sequence of events unfolds as follows.

1) Merging firms hand in a merger proposal (with or without remedies) to the ${ }^{2}$ One brand is associated with one good.

${ }^{3}$ In practice, the merged entity should sell their divestitures to other firm(s). However, in our model there is no discount factor of the transaction, so the transfer of trading divestiture is completely internalized in social welfare. Moreover, we exclude the free entry. So firm 3 is the unique possible firm which can get divestitures from the merged entity.

${ }^{4}$ Consumers preferences can be expressed as $V=U+y$, so a partial equilibrium analysis is fully justified.

${ }^{5}$ The cost is normalized to 0 . 
antitrust authority.

2) The antitrust authority decides whether to approve the merger proposal or not.

3) Competition takes place.

This timing is in line with the European Commission's Merger Control Procedures $^{6}$ and reflects merging procedures in most countries and areas. In the following, we emphasize some remarks.

It is important to distinguish between merger process and antitrust process. This paper focuses on the merger process. The crucial difference is that in the merger process the merging firms provide a merger proposal (with or without remedies), and then the antitrust authority decides to approve or block it. In the antitrust process, the antitrust authority assigns firms some remedial requirements. Put differently, in the merger process, the merger policy is not an industrial policy, the antitrust authority is not an industrial regulator, and the antitrust authority's purpose is not to re-structure the post-merger market. This is consistent with the merger procedures in most countries and areas. For example, the European Commission (2013a) states that "if the Commission has concerns that the merger may significantly affect competition, the merging companies may offer remedies ('commitments'), i.e., propose certain modifications to the project that would guarantee continued competition on the market" ${ }^{7}$. Therefore during the merging procedure the antitrust authority will not increase "over-fixing" stage problem mentioned in some contributions (e.g., Nocke \& Whinston, 2010), it only has a veto over merger proposals ${ }^{8}$.

The object of the antitrust authority is social welfare. This is in line with the antitrust practice in some countries. For example, in Canada, Australia and New Zealand, the antitrust authorities lean to a social welfare standard (Motta, 2004, Chapter 1). Secondly, even in the EU and the US where the antitrust authorities tend to adopt a consumer surplus standard, in some cases, they review mergers under a different (public interest) standard and the interactions among agencies with overlapping jurisdictions affect the review process in various ways (e.g., European Commission, 2004, Article 11).

In principle, remedial divestitures can be assigned to the existing competitor(s) or to the new entrant(s). In this paper, we only consider the merger with divestiture to an existing competitor. This assumption rules out the "buy them off" effect described in Cabral (2003), which means a new entrant is unwilling to introduce a new product variant. Moreover, most of new entrants cannot survive in the market for long time (Papandropoulos \& Tajana, 2006).

${ }^{6}$ Here we only focus on the Phase I stage and ignore the Phase II stage in the EU, because there are very few merger cases go to the Phase II stage, for example, Verge (2010) shows that 3.4\% of mergers notified between 1999 and 2008 went into Phase II. Moreover, the rules in the Phase I stage and the Phase II stage are slightly different. In the Phase II stage, merging firms and the antitrust authorities may bargain over remedies. In the US, the similar two-stage procedure is called the First Request stage and the Second Request stage.

${ }^{7}$ Emphasis added.

${ }^{8}$ At least in the Phase I stage. 
We adopt the Subgame Perfect Nash Equilibrium (SPNE) as the equilibrium concept and solve the game by backward induction.

\section{No Merger}

The benchmark solution is the three-firm Cournot oligopoly equilibrium without merger.

Lemma 1 The pre-merger firm's profit is $\pi^{N M}=[(1+\mu)(3+\mu)] /\left[(6+4 \mu)^{2}\right]$. The pre-merger social welfare is $S W^{N M}=U^{N M}=[3(1+\mu)(9+5 \mu)] /\left[2(6+4 \mu)^{2}\right]$.

Lemma 1 does not only show the equilibrium of pre-merger market, but also unfolds the results when the antitrust authority blocks the merger.

\section{Merger with Given Divestiture}

The number of brands that the merged entity can keep is $k \in(n, 2 n]$. On the one hand, the maximal $k$ is $2 n$, it is a full merger, i.e., a merger without remedies. On the other hand, $k$ must be higher than $n$, because brands are only given from the target firm (firm 2) and the merged entity keeps at least $n$ brands of the acquirer (firm 1).

Lemma 2 The antitrust authority approves a merger with a given divestiture, if and only if

$$
X \geq U^{N M}-U(k) \equiv X_{U}^{*}(k) .
$$

The function $X_{U}^{*}(k)$ plays a crucial role in the analysis and therefore we discuss its properties. $X_{U}^{*}(k)=U^{N M}-U(k)$ is $U$-shaped and symmetric at $k=\frac{3}{2} n$. This follows because $U(k)$ is inverted $U$-shaped, symmetric and maximized at $k=\frac{3}{2} n$. From consumers' point of view, the "best" result is that the two postmerger firms share the $3 n$ brands equally. The further $k$ departs from $\frac{3}{2} n$ (whatever to which direction), the smaller consumers' utility. More precisely, if the merged entity keeps $\left(\frac{3}{2} n+d\right)$ brands, where $d \in\left(0, \frac{1}{2} n\right)$, the unique competitor will keep $\left(\frac{3}{2} n-d\right)$ brands, because the number of total brands does not change before and after merger. Then the antitrust authority, which cares about the social welfare, is indifferent whether the merged entity keeps $\left(\frac{3}{2} n-d\right)$ varieties or $\left(\frac{3}{2} n+d\right)$ varieties.

Given $k$, the antitrust authority can determine the value of $X_{U}^{*}(k)$. Then, as long as $X \geq X_{U}^{*}(k)$, i.e., the condition (4) is fulfilled, the antitrust authority approves the merger with remedies, as showed in the shaded area in Figure 1. When $k=\frac{3}{2} n$, the two post-merger firms share the brands equally. This is the 
best scenario for consumers, and the requirement for the efficiency gains is the most relaxed. When $k=n$ or $k=2 n$, they are the worst cases for consumers, so the antitrust authority sets the hardest condition on the efficiency gains to the merging entity. When the efficiency gains $x$ cannot fulfill the antitrust authority's conditions, which is the area below the curve $X_{U}^{*}(k)$, the merged entity's lessened market power by remedies still overwhelms the efficiency gains from merger, so that the social welfare is reduced and the merger is blocked even with remedies.

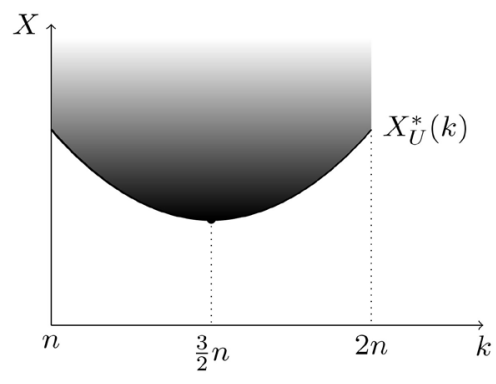

Figure 1. The merger with exogenous divestiture.

\section{Merger with Endogenous Divestiture}

We next consider the case where the divestiture to a competitor is endogenously proposed by merging firms. The merging firms' purpose is to find the optimally acceptable number of brands they will keep to maximize the merged entity's profit, which means first the merging firms have the incentive to merge; second, the antitrust authority approves the merger. The constraint (4) still works in this section, meanwhile another constraint ensures that the merging firms have incentives to hand in the merger proposal, which means the merged entity's net profit is not less than their joint pre-merger profits,

$$
\Pi_{m}(k)+X \geq 2 \Pi^{N M} .
$$

Rewriting constraint (5) yields

$$
X \geq 2 \Pi^{N M}-\Pi_{m}(k) \equiv X_{\Pi}^{*}(k) .
$$

$X_{\Pi}^{*}(k)$ is decreasing in $k$, because $\Pi_{m}(k)$ is increasing in $k$. This indicates that the more brands the merged entity keeps, the higher profit it gets, as it can produce more brands with the efficiency gains $X$. The higher profit induces that the merging firms set a more relaxed barrier to hand in their proposal.

The merging firms' maximization problem is

$$
\max _{k} \Pi_{m}(k)+X \text { s.t. (4) and (6). }
$$

According to the features of $\Pi_{m}(k)$ discussed above, if there were no constraints on merging firms, one can get the optimal solution immediately: $k^{*}=2 n$, which means that the merged entity keeps all brands from both the acquirer and the target firm. Therefore, this maximization problem can be translated into two steps. First, the merging firms find out the feasible and ac- 
ceptable range of $k$. Second, the maximal $k$ from the range is the optimal solution to the maximization problem.

Proposition 1 The merger decisions with optimal endogenous divestiture are following.

A. The merger without remedies (full merger) is cleared if and only if $X \in\left[X_{U}^{*}(2 n), \infty\right)$.

B. The merger with remedies (the divestiture of brands to the existing competitor) is cleared if

1) $\mu<\mu_{1}$ and $X \in\left[X_{U}^{*}(\tilde{k}), X_{U}^{*}(2 n)\right)$, where $\tilde{k} \in\left(\frac{3}{2} n, 2 n\right)$ and $\mu_{1}=\frac{1}{2}(7+\sqrt{97})$;

2) $\mu \geq \mu_{1}$ and $X \in\left[X_{U}^{*}\left(\frac{3}{2} n\right), X_{U}^{*}(2 n)\right)$.

The merged entity has $\max \left\{X_{U}^{*-1}(X), \frac{3}{2} n\right\}$ brands.

C. The merger is blocked if

1) $\mu<\mu_{1}$ and $X \in\left(0, X_{U}^{*}(\tilde{k})\right)$, where $\tilde{k} \in\left(\frac{3}{2} n, 2 n\right)$;

2) $\mu \geq \mu_{1}$ and $X \in\left(0, X_{U}^{*}\left(\frac{3}{2} n\right)\right)$.

When constraints (4) and (6) are both fulfilled, the efficiency gains $X$ must locate above both curves $X_{\Pi}^{*}(k)$ and $X_{U}^{*}(k)$. In the following, we first explain Proposition 1 with figures.

Figure 2 shows the case that the merging firms only provide a full merger proposal and the antitrust authority always approves the merger. For example, if the merging firms' efficiency gains are $X=X_{1}>X_{\Pi}^{*}(2 n)$, the feasible range of the number of brands that they can keep is $k \in\left[k_{1}, 2 n\right]$. In the feasible range, the optimal $k$ to maximize the merging firms' profit is $2 n$. This rationale that the full merger is approved goes through when $X \in\left[X_{\Pi}^{*}(2 n), \infty\right)$. In this case, the antitrust authority welcomes mergers more than the firms do, because the condition that the antitrust authority sets to the efficiency gains is always lower than the one set by firms. So as long as efficiency gains are not high enough, i.e., $X<X_{\Pi}^{*}(2 n)$, firms will not provide merger proposals at all. Based on the form of the utility function and the conditions on the parameters, this case does not

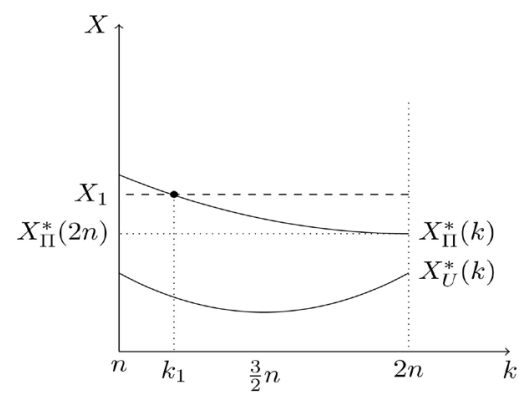

Figure 2. The merger case without remedies. 
hold, i.e., it is impossible that the merging firms only face two options: a full merger and no merger. There are always some scopes for a merger with remedies. In the following, we consider the possible merger cases with remedies.

Figure 3 shows that when $\mu$ is low enough, i.e., $\mu<\mu_{1}$, there is always one crossing point $k=\tilde{k}$ lies between $\frac{3}{2} n$ and $2 n$, independent on whether there is another crossing point lies between $\left(n, \frac{3}{2} n\right)$ or not. In these two cases, we can divide $X$ into three ranges. When $X$ is high enough, i.e., $X_{U}^{*}(2 n) \leq X$, the full merger is approved. When $X$ is at the middle range, i.e., $X_{U}^{*}(\tilde{k}) \leq X<X_{U}^{*}(2 n)$, the merger with remedies are approved and the number of brands that the merged entity keeps is $k=X_{U}^{*-1}(X)$, where $k \in[\tilde{k}, 2 n)$. When $X$ is low enough, i.e. $X<X_{U}^{*}(\tilde{k})$, the merger is blocked or the firms do not provide any merger proposal. This shows that although we define the range of $k$ as $(n, 2 n]$, actually the feasible range is $k \in\left[\frac{3}{2} n, 2 n\right]$, because $k \in[\tilde{k}, 2 n) \subset\left[\frac{3}{2} n, 2 n\right]$. The intuition is that remedies are proposed by merging firms. Put differently, the "worst acceptable" remedies that merging firms can make is to keep $\frac{3}{2} n$ varieties, i.e., to have the same number of brands as their unique competitor after merger.

The rationale is the same as the following two cases showed in Figure 4. The condition on the efficiency gains for the full merger does not change. Because the two cases showed in Figure 4 indicate the situation that $\mu$ is high enough, i.e., the brands are closer to perfect substitutes, then the competition between the two firms after merger is lighter than the one with more independent goods, the ranges of approved merger with remedies are enlarged and the ranges of block the merger are smaller than Figure 3, as showed in Figure 4 the entire range of $\left[\frac{3}{2} n, 2 n\right]$ is feasible for merger with remedies.

Simplifying the cases showed in Figure 3 and Figure 4, one can focus on range $k \in\left[\frac{3}{2} n, 2 n\right]$ and get Figure 5 . The thick curves show the paths of optimal $k$.

Summarizing Proposition 1, we have Table 2.

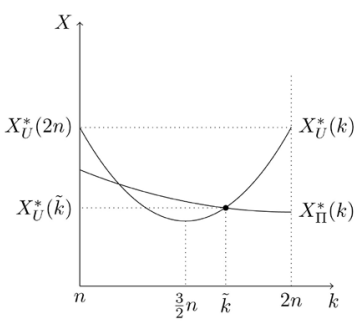

(a)

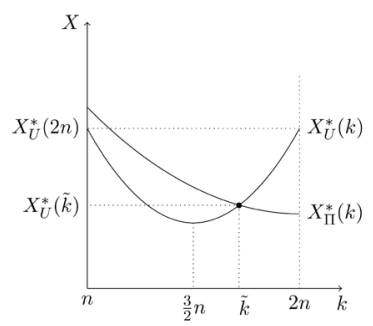

(b)

Figure 3. The merger case with partial remedies. (a) when two crossing points in $\left(\frac{3}{2} n, 2 n\right) ;(\mathrm{b})$ unique crossing point in $\left(\frac{3}{2} n, 2 n\right)$. 


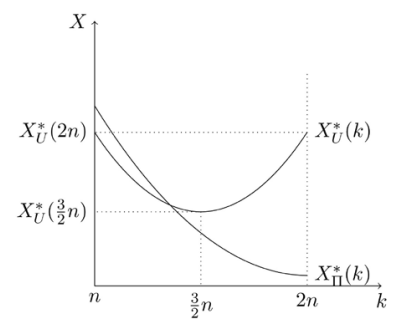

(a)

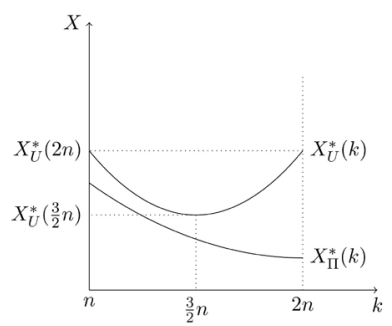

(b)

Figure 4. The merger case with all possible remedies. (a) one crossing point in $\left(n, \frac{3}{2} n\right)$;

(b) no crossing point in $(n, 2 n)$.

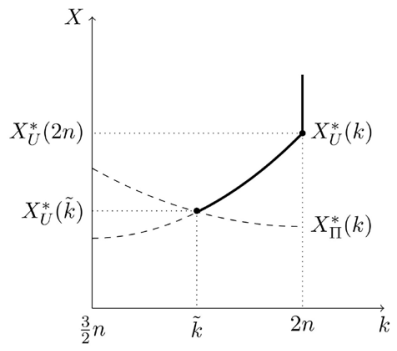

(a)

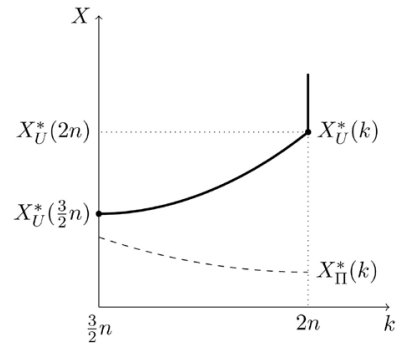

(b)

Figure 5. The path of optimal $k$. (a) when $\mu$ is low; (b) when $\mu$ is high.

Table 2. The conditions for mergers in 3-pre-merger-firms case.

\begin{tabular}{cccc}
\hline & Block & Merger with remedies & Full merger \\
\hline$\mu<\mu_{1}$ & $X \in\left(0, X_{U}^{*}(\tilde{k})\right)$ & $X \in\left[X_{U}^{*}(\tilde{k}), X_{U}^{*}(2 n)\right)$ & \\
$\mu \geq \mu_{1}$ & $X \in\left(0, X_{U}^{*}\left(\frac{3}{2} n\right)\right)$ & $X \in\left[X_{U}^{*}\left(\frac{3}{2} n\right), X_{U}^{*}(2 n)\right)$ & \\
\hline
\end{tabular}

Table 2 shows clearly that, without remedies, the merger is privately and socially desirable only when the efficiency gains $X$ is high enough, merger with remedies is a powerful and efficient tool to lessen the merged entity's market power, so that the requirement on efficiency gains to approve the merger is much lower. As a consequence, remedies increase the scope for privately and socially desirable mergers.

Another significant difference between our model and the most of existing theoretical literatures on merger with remedies is that we consider the differentiated goods rather than homogeneous goods. As Proposition 1 shows, the degree of substitutability $\mu$ also plays an important role in the merger policy. When $\mu$ is high enough, i.e., the brands are closer to the perfect substitute goods, the scope of the approved merger is larger than the case that the brands are closer to the independent goods. One straightforward intuition might be that when the brands are closer to independent goods, the requirements for approving merger should be lighter, and our result is counterintuitive. But this intuition 
is not complete. In our model, we consider that all the brands in the market are symmetrical substitutes, so the brands that the competitor has are also the substitutes' goods. Therefore, when $\mu$ is higher than the benchmark $\mu_{1}$, the range of approved merger is larger.

\section{Extensions}

If there are more than three firms, the merging firms do not only decide how many divestitures give to competitor(s), but also how to distribute a certain number of divestitures among competitors. Consider now four symmetric pre-merger firms. All the assumptions are the same as in the case of three pre-merger firms, but the total number of brands in the market is $4 n$ now. Consider a one-shot merger between firm 1 as an acquirer and firm 2 as a target firm. The merged entity has two options: either to give divestitures to one of the two post-merger competitors, namely, firm 3, or to divide divestitures to both, i.e., firm 3 and firm 4 .

Lemma 3 If there are four symmetric pre-merger firms,

A. When $\mu>\bar{\mu}(n)$, the merged entity gives the divestitures to only one competitor.

B. When $\mu<\bar{\mu}(n)$, the merged entity gives the divestitures symmetrically to both competitors.

Lemma 3 shows the benchmark of two extreme cases, the merged entity either gives the divestitures to one competitor or shares the divestitures equally between the two competitors. The intuition is that, when the brands are closer to perfect substitutes, the merged entity prefers to give the divestitures to one competitor, in the sense that only makes one competitor more efficient and keeps another one same as pre-merger. When the brands are closer to independent goods, the merged entity prefers the more symmetric competition in the market. Moreover, when the merged entity gives the divestitures to only one competitor, it is similar with Proposition 1, only the values of benchmarks change. When the merged entity gives the divestitures to both competitors, another question arises: how to distribute a certain number of divestitures among competitors, which is more complicated. The intuitions are following. The "best" result for consumers should be all the three post-merger firms share the brands equally, so in this case, $X_{U}^{*}(k)$ is minimized at $k=\frac{4}{3} n$. But meanwhile even when the merged entity keeps $k=\frac{4}{3} n$ brands, it is possible that the number of brands that other two competitors have is not $\frac{4}{3} n$, because the merged entity may not distribute $\frac{2}{3} n$ brands as divestitures equally between firm 3 and firm 4 .

\section{Concluding Remarks}

In this paper, we attempt to shed some light on merger policy with structural 
remedies, a field of research which is in line with the practical trends of mergers in recent 20 years but on which still there is very little theoretical literature. To the best of our knowledge, this is the first theoretical paper which tries to analyze one popular merger trend in practice: mergers with structural divestitures of brands to the existing competitor(s). Under certain conditions, a merger with remedies, as a powerful tool in merger policy, increases the scope for profitable mergers because of the efficiency gains from the merger, meanwhile does not harm social welfare because of the merged entity's lessened market power, so the merger with remedies is both privately and socially desirable. More precisely, the remedial offers must be larger when the merger's efficiency gains are smaller, which mirrors the proportionality principle in remedy regulations. Another important result is that when goods are closer to perfect substitutability, the merging firms are more inclined to give some brands to competitor(s), because the markup on each brand is lower. Therefore, the range of the efficiency gains which allows the merger with remedies to be approved is larger. This paper provides theoretical suggestions to antitrust authorities and shows that there is some room to increase social welfare.

Except for the more general case we discussed in Section 6, there is some scope for further research. For example, this paper models the Phase I in the EU or the First Request in the US. However, as mentioned before, there is a (small) portion of merger cases which go to Phase II or the Second Request. As Farrell (2003) points out, Phase II is characterized by a bargaining process between the merging firms and the antitrust authority. We expect that some merger proposals, which are blocked under the setting of this paper, could be cleared if further negotiations are allowed between the merging firms and the antitrust authority.

\section{Acknowledgements}

I thank Helmut Bester, Raffaele Fiocco, Sergei Izmalkov, Carlo Reggiani and Roland Strausz for helpful comments and suggestions. We are also grateful to the participants at SFB-TR15 Young Researchers Workshop 2014 in Berlin, "Doktor and Innenund Forschungsseminar Mikroökonomie" in Berlin and IOSE 2017 in Saint Petersburg.

\section{Conflicts of Interest}

The authors declare no conflicts of interest regarding the publication of this paper.

\section{References}

Bougette, P., \& Turolla, S. (2008). Market Structures, Political Surroundings, and Merger Remedies: An Empirical Investigation of the EC's Decisions. European Journal of Law and Economics, 25, 125-150. https://doi.org/10.1007/s10657-007-9042-6

Cabral, L. (2003). Horizontal Mergers with Free-Entry: Why Cost Efficiencies May Be a 
Weak Defense and Asset Sales a Poor Remedy. International Journal of Industrial Organization, 21, 607-623. https://doi.org/10.1016/S0167-7187(02)00145-5

Dertwinkel-Kalt, M., \& Wey, C. (2012). The Effects of Remedies on Merger Activity in Oligopoly. DICE Discussion Papers No. 81, Düsseldorf: Heinrich-Heine University. https://doi.org/10.2139/ssrn.2338407

Duso, T., Gugler, K., \& Szücs, F. (2013). An Empirical Assessment of the 2004 EU Merger Political Reform. Economic Journal, 572, F596-F619. https://doi.org/10.1111/ecoj.12081

Duso, T., Gugler, K., \& Yurtoglu, B. B. (2011). How Effective Is European Merger Control? European Economic Review, 55, 980-1006. https://doi.org/10.1016/j.euroecorev.2011.04.003

European Commission (2001). Commission Notice on Remedies Acceptable under Council Regulation (EC) No 4046/89 and under Commission Regulation (EC) No 447/98. Official Journal, 2 March 2001, C 68.

European Commission (2004). Merger Regulation 139/2004, Article 11.

European Commission (2008). Commission Notice on Remedies Acceptable under Council Regulation (EC) No 139/2004 and under Commission Regulation (EC) No 802/2004. Official Journal, C 267.

European Commission (2014). Commission Staff Working Document White Paper SWD (2014) 221 Final.

https://ec.europa.eu/competition/consultations/2014_merger_control/staff_working_d ocument_en.pdf

European Commission (2013a). Competition: Merger Control Procedures. http://ec.europa.eu/competition/publications/factsheets/merger.en.pdf

European Commission (2013b). EU Competition Law: Rules Applicable to Merger Control. http://ec.europa.eu/competition/mergers/legislation/legislation.html

Farrell, J. (2003). Negotiation and Merger Remedies: Some Problems. In F. Leveque, \& H. Shelanski (Eds.), Merger Remedies in American and European Union Competition Law. London: Edward Elgar Publishers. https://doi.org/10.2139/ssrn.495602

Medvedev, A. (2007). Structural Remedies in Merger Regulation in a Cournot Framework. Working Paper.

Motta, M. (2004). Competition Policy: Theory and Practice. Cambridge: Cambridge University Press. https://doi.org/10.1017/CBO9780511804038

Motta, M., Polo, M., \& Vasconcelos, H. (2003). Merger Remedies in the European Union: An Overview. In F. Leveque, \& H. Shelanski (Eds.), Merger Remedies in American and European Union Competition Law. London: Edward Elgar Publishers.

Nocke, V., \& Whinston, M. D. (2010). Dynamic Merger Review. Journal of Political Economy, 118, 1200-1251. https://doi.org/10.1086/658161

OECD (2011). Remedies in Merger Cases. Paris: OECD Policy Roundtables. http://www.oecd.org/daf/competition/competition-remedies-in-cross-border-merger-c ases.htm

Papandropoulos, P., \& Tajana, A. (2006). The Merger Remedies Study in Divestiture We Trust? European Competition Law Review, 27, 443-454.

Shubik, M., \& Levitan, R. (1980). Market Structure and Behavior. Cambridge, MA: Harvard University Press. https://doi.org/10.4159/harvard.9780674433403

UK Competition Commission (2008). Merger Remedies: Competition Commission Guidelines. 
https://www.gov.uk/government/uploads/system/uploads/attachment_data/file/284415 Icc8.pdf

Verge, T. (2010). Horizontal Mergers, Structural Remedies, and Consumer Welfare in a Cournot Oligopoly with Assets. Journal of Industrial Economics, 58, 723-741. https://doi.org/10.1111/j.1467-6451.2010.00432.x

Vasconcelos, H. (2010). Efficiency Gains and Structural Remedies in Merger Control. Journal of Industrial Economics, 58, 742-766. https://doi.org/10.1111/j.1467-6451.2010.00436.x

Williamson, O. E. (1968). Economies as an Antitrust Defense: The Welfare Tradeoffs. American Economic Review, 58, 18-36. 


\section{Appendix}

This Appendix collects the proofs.

Proof of Lemma 1 Based on the more general gross profit function 3, one can get the pre-merger firm's gross profit as $\Pi_{j}=\sum_{i=(j-1) n+1}^{j n}\left[p_{i}\left(q_{1}, \cdots, q_{3 n}\right) q_{i}\right]$. Plugging (2) into this profit function and maximizing it by choosing outputs simultaneously, i.e., $\partial \Pi_{j} / \partial q_{i}=0$ yields the Cournot equilibrium quantity for each brand $q^{N M}=(1+\mu) /[n(6+4 \mu)]$. Plug $q^{N M}$ into (2), one can get the equilibrium price for each brand $p^{N M}=(3+\mu) /(6+4 \mu)$.

Each firm realizes the same profit $\Pi^{N M}=n p^{N M} q^{N M}=\frac{(1+\mu)(3+\mu)}{(6+4 \mu)^{2}}$.

Following the utility function (1), the pre-merger equilibrium social welfare is $S W^{N M}=U^{N M}=\sum_{i=1}^{3 n} q_{i}-\frac{3 n}{2(1+\mu)}\left[\sum_{i=1}^{3 n} q_{i}^{2}+\frac{\mu}{3 n}\left(\sum_{i=1}^{3 n} q_{i}\right)^{2}\right]=\frac{3(1+\mu)(9+5 \mu)}{2(6+4 \mu)^{2}}$.

Combining terms yields the result in the lemma.

Proof of Lemma 2 When the divestiture to a competitor is exogenous, at the stage (II) of the timing, the antitrust authority approves the merger as long as the post-merger social welfare is not smaller than the pre-merger one, i.e. $U(k)+X \geq U^{N M}$. Rewriting this condition yields $X \geq U^{N M}-U(k)$, which is result of Lemma 2 .

Proof of Proposition 1 Based on the more general gross profit function (3), the two post-merger firms' profits are

$$
\begin{gathered}
\Pi_{m}=\sum_{i=1}^{k}\left[p_{i}\left(q_{1}, \cdots, q_{3 n}\right) q_{i}\right]+X, \\
\Pi_{d}=\sum_{i=k+1}^{3 n}\left[p_{i}\left(q_{1}, \cdots, q_{3 n}\right) q_{i}\right],
\end{gathered}
$$

where $m$ indicates the merged entity, $d$ indicates the competitor which gets the divestiture, i.e., firm 3. Using the same procedure in Proof of Lemma 1, one can get the equilibrium quantities in the post-merger market.

$$
\begin{aligned}
& q_{m}=\frac{(1+\mu)[3 n(2+\mu)-k \mu]}{3 k \mu^{2}(3 n-k)+36 n^{2}(1+\mu)}, \\
& q_{d}=\frac{(1+\mu)(6 n+m \mu)}{3 k \mu^{2}(3 n-k)+36 n^{2}(1+\mu)} .
\end{aligned}
$$

Pluging these two values into the inverse demand function (2), the gross consumer surplus function (1) and the firms' profit functions showed above, at the end, we can get

$$
\begin{gathered}
X_{\Pi}^{*}(k)=\frac{1+\mu}{18}\left[\frac{9(3+\mu)}{(3+2 \mu)^{2}}-\frac{2 k(3 n+k \mu)(k \mu-3 n(2+\mu))^{2}}{\left(k^{2} \mu^{2}-3 k n \mu^{2}-12 n^{2}(1+\mu)\right)^{2}}\right], \\
X_{U}^{*}(k)=\frac{1}{72}(1+\mu)\left(\frac{27(9+5 \mu)}{(3+2 \mu)^{2}}-\left(4 \left(8 k^{4} \mu^{3}-48 k^{3} n \mu^{3}\right.\right.\right.
\end{gathered}
$$




$$
\begin{aligned}
& +972 n^{4}(1+\mu)+27 k n^{3} \mu(8+19 \mu) \\
& \left.\left.\left.+9 k^{2} n^{2} \mu(-8+\mu(-19+8 \mu))\right)\right) /\left(k^{2} \mu^{2}-3 k n \mu^{2}-12 n^{2}(1+\mu)\right)^{2}\right) .
\end{aligned}
$$

As $\partial X_{\Pi}^{*}(k) / \partial k<0, \partial X_{U}^{*}(k) / \partial k<0$ when $k \in\left(n, \frac{3}{2} n\right]$ and $\partial X_{U}^{*}(k) / \partial k>0$ when $k \in\left[\frac{3}{2} n, 2 n\right]$, the curve $X_{\Pi}^{*}(k)$ and the curve $X_{U}^{*}(k)$ cross at most twice when $k \in(n, 2 n]$. We can avoid solving the maximization problem in a standard way, and only compare the values of $X_{\Pi}^{*}(k)$ and $X_{U}^{*}(k)$ at three crucial points, $k=n, k=\frac{3}{2} n$ and $k=2 n$. Moreover, we can split the proof into 3 cases according to the final results of mergers.

Case 1 When the results are either full merger or no merger.

According to Figure 2, one can get

$$
\begin{aligned}
X_{U}^{*}(n) & <X_{\Pi}^{*}(n) \\
X_{U}^{*}\left(\frac{3}{2} n\right) & <X_{\Pi}^{*}\left(\frac{3}{2} n\right), \\
X_{U}^{*}(2 n) & \geq X_{\Pi}^{*}(2 n) .
\end{aligned}
$$

These three conditions cannot hold simultaneously because of the utility function we use and the conditions on the parameters, i.e., $\mu>0, n \geq 2$ and $k \in(n, 2 n]$.

Case 2 When the merger with remedies is feasible but the range of feasible $k$ is smaller than $\left[\frac{3}{2} n, 2 n\right]$.

Originally there are two subcases showed in Figure 3, in the main text of the paper we discuss them and reduce them into one case showed in Figure 5(a). So based on the more strict range of $k$, we have

$$
\begin{aligned}
X_{U}^{*}\left(\frac{3}{2} n\right) & <X_{\Pi}^{*}\left(\frac{3}{2} n\right), \\
X_{U}^{*}(2 n) & >X_{\Pi}^{*}(2 n) .
\end{aligned}
$$

These two inequalities hold simultaneously as long as $\mu<\mu_{1} \equiv(7+\sqrt{97}) / 2$, meanwhile by $X_{U}^{*}(k)=X_{\Pi}^{*}(k)$, we can get the benchmark

$$
\begin{aligned}
\tilde{k}= & \frac{3 n}{2 \mu\left(72+51 \mu-\mu^{2}\right)} \\
& \times\left[\sqrt{5184+17280 \mu+19152 \mu^{2}+8352 \mu^{3}+1065 \mu^{4}-54 \mu^{5}+\mu^{6}}\right. \\
& \left.-\left(72+24 \mu-19 \mu^{2}+\mu^{3}\right)\right] .
\end{aligned}
$$

Case 3 When the merger with remedies is feasible and the range of feasible $k$ is $\left[\frac{3}{2} n, 2 n\right]$.

Similarly with Case 2, using the reduced case showed in Figure 5(b), we have 


$$
\begin{aligned}
& X_{U}^{*}\left(\frac{3}{2} n\right) \geq X_{\Pi}^{*}\left(\frac{3}{2} n\right), \\
& X_{U}^{*}(2 n)>X_{\Pi}^{*}(2 n) .
\end{aligned}
$$

These two inequalities hold simultaneously as long as $\mu>\mu_{1}$.

Summarizing Case 1 - 3, one can get Proposition 1.

Proof of Lemma 3 When there are 4 pre-merger firms, the equilibrium premerger outcomes are:

$$
\begin{gathered}
q^{N M}=\frac{1+\mu}{n(8+5 \mu)} \\
p^{N M}=\frac{4+\mu}{8+5 \mu} \\
\Pi^{N M}=\frac{(1+\mu)(4+\mu)}{(8+5 \mu)^{2}} \\
U^{N M}=\frac{12(1+\mu)(2+\mu)}{(8+5 \mu)^{2}}
\end{gathered}
$$

When only one competitor gets the divestiture from the merged entity, then the equilibrium outcomes are:

$$
\begin{gathered}
q_{1}^{m}=\frac{(1+\mu)(8+\mu)(8 n-k \mu+3 n \mu)}{A} \\
q_{1}^{d}=\frac{(1+\mu)(8+\mu)(8 n+k \mu)}{A} \\
q_{1}^{c}=\frac{(1+\mu)(8+\mu)(8 n-k \mu+3 n \mu)}{n A} \\
\Pi_{1}^{k}=\frac{k(1+\mu)(8+\mu)^{2}(4 n+k \mu)(k \mu-n(8+3 \mu))^{2}}{A^{2}}
\end{gathered}
$$

where $A=-4 k^{2} \mu^{2}(6+\mu)+12 k n \mu^{2}(6+\mu)+8 n^{2}(64+\mu(64+9 \mu)), \quad q_{1}^{d} \quad$ indicates the quantity produced by the competitor which gets the divestiture, and $q_{1}^{c}$ indicates the quantity produced by the competitor which does not get.

When there are two competitors get the same divestitures from the merged entity, then the equilibrium outcomes are:

$$
\begin{gathered}
q_{2}^{m}=\frac{(1+\mu)(4 n(4+\mu)-k \mu)}{2 C} \\
q_{2}^{d}=\frac{(1+\mu)(8 n+k \mu)}{C} \\
\Pi_{2}^{k}=\left(k^{2} \mu(-1+\mu(-3+2(-1+8 n) \mu))\right. \\
-16 n^{2}(-4+\mu(-9-5 \mu+8 n(4+3 \mu))) \\
+16 k n(1+\mu(3+\mu(3+\mu-2 n(1+2 \mu))))) /(2(1+\mu) C)
\end{gathered}
$$


$\partial \Pi_{1}^{k} / \partial k>0$ and $\partial \Pi_{2}^{k} / \partial k>0$, so using the same method as before, we avoid solving the general inequality, but only compare their values at $k=n$ and $k=2 n$. Solving the pair of inequalities $\Pi_{1}^{n} \geq \Pi_{2}^{n}$ and $\Pi_{1}^{2 n} \geq \Pi_{2}^{2 n}$, we have $\mu \geq \bar{\mu}(n)$. 